\title{
Magnitude and Determinants of Treatment Outcome Among Surgically Treated Patients with Intestinal Obstruction at Public Hospitals of Wolayita Zone, Southern Ethiopia: Across Sectional Study
}

\author{
Muhaba Batebo \\ Homecho Primary Hospital \\ Bereket Loriso \\ Wolayita Sodo University, Ethiopia \\ Tilahun Beyene \\ Wachamo University \\ Yosef Haile ( $\nabla$ yoseph.haile@amu.edu.et ) \\ Arba Minch University \\ Samuel Hailegebreal \\ Arba Minch University
}

\section{Research Article}

Keywords: Surgical outcome, intestinal obstruction, Wolayita Zone

Posted Date: January 3rd, 2022

DOI: https://doi.org/10.21203/rs.3.rs-1140922/v1

License: (c) (i) This work is licensed under a Creative Commons Attribution 4.0 International License. Read Full License 


\section{Abstract}

Background: Procedures to treat intestinal obstruction range from minimally invasive laparoscopic surgery to more complicated open surgical procedures. It may end with high morbidity and mortality because of different reasons. It is very important to know about the determinants of favorable outcome of surgical management for intestinal obstruction however, little is known about this problem at public hospitals of Southern Ethiopia.

Methods: Facility based cross sectional study was conducted. A total of 230 medical records which fulfill the inclusion criteria were used for this study. Variables with $p$ value of less than 0.25 in the bivariate analysis were entered in multivariable logistic regression to control confounding. Finally, odds ratio with $95 \%$ confidence interval was used to identify variables which were significantly associated with dependent variable.

Results: According to this study the magnitude of favorable surgical management outcome of intestinal obstruction was $177(77.0 \%)$ [95\% Cl, 71.4, 82.4]. Having small bowel obstruction (AOR=2.49) [95\% $\mathrm{Cl} 1.91,5.12]$, having simple bowel obstruction $(\mathrm{AOR}=4.32)[95 \% \mathrm{Cl}, 2.00,9.35]$, early presentation of patients $(\mathrm{AOR}=4.44)[95 \%$ $\mathrm{Cl}, 1.99,9.92]$ and intraoperative procedure other than resection and anastomosis was performed $(\mathrm{AOR}=0.45)$ $[95 \% \mathrm{Cl}, .21, .96]$ were significantly associated with favorable outcome among surgically treated patients.

Conclusion: The overall magnitude of favorable surgical management outcome of intestinal obstruction was moderate compared to other study. Having small bowel obstruction, having simple bowel obstruction, other procedure other than resection and anastomosis done, and early presentation of patients were significant predictors. Physicians should diagnose intestinal obstruction early and appropriate interventions should be taken on time before the complication happened. On time consultation and decision at the hospital setting is also recommended.

\section{Introduction}

Intestinal obstruction is a gastro-intestinal condition in which digested material is prevented from passing normally through the bowel. It is inability of forward propulsion of intestinal content and the second causes of acute abdomen next to acute appendicitis. (1-4).

Globally, intestinal obstruction accounts for approximately 15 percent of all visits of emergency department for acute abdominal pain. The occurrence and etiology of bowel obstruction throughout the world varied depending on ethnicity, age group, dietary habits, and geographic location, among other factors $(7,8)$. In the United States, $5 \%$ of all large bowel obstructions (LBOs) are caused by colonic volvulus, making it the third most common cause of LBO after cancer and diverticular disease in adult patients. In this country over 300,000 patients are estimated to undergo surgery to treat adhesion-induced small bowel obstruction annually. In some developing countries, including India, Pakistan and Brazil, sigmoid volvulus alone has been reported to account for $20-30 \%$ of all intestinal obstructions (6).

According to different study, colorectal cancer is responsible for $60-70 \%$ of all large bowel obstructions, while diverticulitis and volvulus account for the majority of the remaining $30 \%$ worldwide. Although possible, abdominal wall hernias and adhesions rarely cause a true, isolated large bowel obstruction. In contrast, small bowel obstruction in most advanced western societies is caused most commonly by adhesions, neoplasms, or abdominal wall hernias. In Ethiopia sigmoid volvulas accounts for over $54 \%$ of intestinal obstructions $(5,6)$. 
Studies in Attat and Ayder Referral Hospital, Mekelle in Ethiopia reported that the magnitude of intestinal obstruction accounts for 30 and 42 percent of all emergency surgically treated patients respectively(9-11). A cross sectional study conducted in Arbaminch general Hospital in southern part of Ethiopia also reported that the overall magnitude of intestinal obstruction was $40.60 \%$ from all emergency surgically treated patients (12).

It is one of the serious surgical emergencies and associated with high mortality and morbidity throughout the World. Its mortality rates range from up to $3 \%$ for simple obstructions to as much as $30 \%$ when there is vascular compromise or perforation of the obstructed bowel, depending on the clinical setting and other related or unrelated co morbidities. In addition, bowel obstruction is frequently a recurrent problem, adding to the overall morbidity of an operation or successful non operative management(6).

Management e of intestinal obstruction was improved since the development of more sophisticated diagnostic tests and imaging machine, but still the condition remains major public health problem especially in developing countries $(11,13,14)$. It is the challenging problem which is determined by many patients 'related and clinical related factors like surgical site infection, wound dehiscence, leakage, pneumonia and sepsis. Many of this unfavorable outcome could be minimized if the factors related with surgical management outcome of intestinal obstruction is predetermined and all the necessary action is taken to prevent the causes associated with it before and after the procedure $(15,16)$.

Surgical management is quoted 'evidence based surgical treatment and a concept on which surgical health professional relied on the updated and well evidenced data to recommend for the patients rightfully on plugging of disease. Physicians are not only expected to perform evidence-based procedure but also, they must understand about the postoperative recovery, the impact of quality of procedure and expected functional outcome. (16).

Though studies have been done to assess the prevalence and causes of intestinal obstruction in Ethiopia, the condition related with the magnitude and determinants of treatment outcome among surgically treated patients with intestinal obstruction is largely remain unstudied especially in southern part of Ethiopia. Hence, the aim of this study was to assess magnitude and determinants of treatment outcome among surgically treated patients with intestinal obstruction at public hospitals in Wolayita Zone, Southern Ethiopia.

\section{Methods And Materials}

\section{Study design, study area and period}

Facility based cross sectional study was conducted. This study was conducted only at Wolayita Sodo University Teaching and Referral Hospital because all cases of intestinal obstruction from other public hospitals in the zone referred to this referral hospital. It provides referral services for patients referred from neighboring zones.

Regarding the staffs, the surgical department of the hospital has 10 general surgeons, 4 orthopedic surgeons, 1 neuro-surgeon, 1 urologist, 1 maxillofacial surgeon, 1 pathologist and 1 HEENT surgeon. In the hospital there are two operation room, two male surgical wards, 1 female surgical ward, 1 pediatric surgical ward, 2 male orthopedic surgical ward, 1 female orthopedic surgical ward and 1 pediatric orthopedic surgical ward which are serving patients with surgical cases. The estimated number of surgeries in the previous year was fifty thousand 
cases. The department has 57 beds in general surgical wards, 36 beds in orthopedics ward. The study was conducted from June 1 to August 30, 2021.

\section{Source population}

All Patient's records with the diagnosis of intestinal obstruction and treated surgically at Wolayita Sodo University Teaching and Referral Hospital in the previous three years (Jan 1, 2018-Jan 30 2021) were the source population.

\section{Study population}

All randomly selected patient's records with the diagnosis of Intestinal Obstruction and managed surgically at Wolayita Sodo University Teaching and Referral Hospital during the study period were study population.

\section{Inclusion and exclusion criteria}

All Patients with any age group admitted with the diagnosis of Intestinal obstruction and treated surgically at Wolayita Sodo University Teaching and Referral Hospital during the study period were included. However, all patients with incomplete data and all patients with missed medical record were excluded.

\section{Sample size determination}

Sample size was calculated using epi info version 7.1 and using the assumption of confidence level of $95 \%$ and power of $80 \%$. Hence, the maximum sample size calculated for this specific study was 246 .

\section{Sampling procedure}

All patients' medical record card who was surgically managed for intestinal obstruction and those which can fulfill the inclusion criteria were collected initially. However, only 230 medical records full filled inclusion criteria. Then the data collectors collected data from all available and complete patients' medical record by using data collection checklist.

\section{Data collection tool and technique}

Checklist that was developed after reviewing different related literatures was used $(8-11,18,22)$. The checklist had six parts socio-economic and demographic characteristics, pre-operative factors, intra-operative factors, and post-operative factors, type of obstruction and causative agents of intestinal obstruction. Data was collected by 5 Bachelor of Science holder nurses using the pre-tested checklist. Two supervisors who were qualified with Bachelor of Science in public health were recruited. The data collectors and supervisors were trained on the data collection tool, approach to the interviews, details of interviewing techniques, respect, and maintaining the privacy and confidentiality.

\section{Study variable}

Surgical management outcomes of intestinal obstruction is a dependent variable while independent variables were socio demographic variables, pre-operative factors such as presenting symptom and progression of symptoms, duration of illness from the onset of symptoms up to surgery, pre-operative diagnosis, comorbidity, preoperative care received, previous abdominal surgery, intraoperative diagnosis and procedure done, type of obstruction, and causative agent. 


\section{Operational definition}

\section{Surgical management outcome of intestinal obstruction}

the condition of the patient after surgery done for intestinal obstruction that was whether she/he had "favorable" or "unfavorable" outcome according to the retrospective secondary data extracted from their medical records.

\section{Favorable outcome}

If the patient was discharged alive and hadn't any history of postoperative complications, it was considered as favorable surgical management outcome.

\section{Unfavorable outcome}

if the patient died or has one or more postoperative complications like dehiscence, surgical site infection, pneumonia, and shock.

\section{Simple bowel obstruction}

when there is no vascular compromise in the intestine and if it is intact otherwise gangrenous.

\section{Duration of illness}

is from onset of illness to time of management decision.

Pre-operative diagnosis: clinical diagnosis before surgery by using presenting symptoms and laboratory diagnosis.

\section{Duration of hospital stay}

time of hospital stay for the patients after surgery performed.

Data quality assurance

Data quality assurance was maintained by performing different measures. To ensure the quality of data two-day training for data collectors and supervisors was given on procedure before data collection regarding surgical outcome of intestinal obstruction, on each part of the tool and ethical consideration. Supervisor/Principal investigator checked the collected data on daily basis in order to maintain its accuracy and completeness. Data collection tools was pretested at Wachamo University Nigist Ellen Memorial Referral Hospital in Hossana using $5 \%$ of the total sample size. Following the pretest any weakness in the structuring of the research instruments was identified, the tools was improved in terms of their clarity, understandability and simplicity in collecting the data required for the study.

\section{Data processing and analysis}

Data was entered into epidata version 7.1 then it was exported to SPSS version 25 for analysis. Descriptive statistics was carried out and frequencies, pie charts and tables were used to present the data. Bivariate and multivariable logistic analysis was conducted. Variables in the bivariate analysis with $p$-value $<0.25$ were the 
candidates for multivariable logistic analysis. Model fitness was good according to Hosmer and Lemshow goodness of fit test $(p=0.58)$. Statistical significance was declared at $p$-value 0.05 with $95 \%$ confidence interval. The magnitude of association between dependent and independent variables was determined by odds ratio with $95 \%$ confidence interval. Finally, the result was presented in text, frequency, percentages, tabulation, and charts.

\section{Results}

\section{Socio-demographic characteristics of study participants.}

In this study, from a total sample size, 230 study participants' data were retrieved from their medical records making a response rate of $93.5 \%$. Around $93(40.4 \%)$ participants were in the age category of $15-40$ followed by the age category 41-60 years. The mean and standard deviation of the respondents' age were 32.47 and \pm 18.85 years respectively. From the study participants more than half 153(66.5\%) were male (Table 1). 
Table 1

Socio-demographic characteristics of study participants at public hospitals of Wolayita Zone, Southern Ethiopia $(n=230)$.

\begin{tabular}{|c|c|c|c|}
\hline Variables & & Frequency & Percent \\
\hline \multirow[t]{5}{*}{ Age category of the respondents } & $<5$ & 37 & 16.1 \\
\hline & $5-14$ & 17 & 7.4 \\
\hline & $15-40$ & 93 & 40.4 \\
\hline & $41-60$ & 68 & 29.6 \\
\hline & $>60$ & 15 & 6.5 \\
\hline \multirow[t]{2}{*}{ Sex } & Male & 153 & 66.5 \\
\hline & Female & 77 & 33.5 \\
\hline \multirow[t]{3}{*}{ Marital status } & Married & 153 & 66.5 \\
\hline & Single & 76 & 33.1 \\
\hline & Divorced & 1 & 0.4 \\
\hline \multirow[t]{4}{*}{ Respondent's religion } & Protestant & 149 & 64.8 \\
\hline & Orthodox & 64 & 27.8 \\
\hline & Catholic & 12 & 5.2 \\
\hline & Muslim & 5 & 2.2 \\
\hline \multirow[t]{2}{*}{ Residence } & Rural & 203 & 88.3 \\
\hline & Urban & 27 & 11.7 \\
\hline \multirow[t]{6}{*}{ Occupational status } & Student & 43 & 18.7 \\
\hline & Government employed & 3 & 1.3 \\
\hline & NGO employed & 1 & 0.4 \\
\hline & Merchant & 46 & 20.0 \\
\hline & Farmer & 77 & 33.5 \\
\hline & Non productive & 60 & 26.1 \\
\hline
\end{tabular}

\section{Lifestyle characteristics of study participants}

This study has shown that none of patients had a history of ever tobacco use even if history of tobacco use in most of the study participants was unknown from their medical records, 13(5.7\%) ever alcohol use, and a history of illicit drug use was unknown for all patients from their medical records (Table 2). 
Table 2

Lifestyle Characteristics of study participants at public hospitals of Wolayita Zone, Southern Ethiopia $(n=230)$.

\begin{tabular}{|llll|}
\hline Variables & & Frequency & Percent \\
\hline Tobacco use & Ever & 0 & 0 \\
\cline { 2 - 4 } & Never & 67 & 29.1 \\
\cline { 2 - 4 } Alcohol use & Unknown & 163 & 70.9 \\
& Ever & 13 & 5.7 \\
\cline { 2 - 4 } & Never & 67 & 29.1 \\
\cline { 2 - 4 } Illicit drug use & Unknown & 150 & 65.2 \\
\cline { 2 - 4 } & Ever & 0 & 0 \\
\cline { 2 - 4 } & Never & 66 & 28.7 \\
\cline { 2 - 4 } & Unknown & 164 & 71.3 \\
\hline
\end{tabular}

\section{Clinical characteristics and causes of intestinal obstruction}

The findings revealed that abdominal pain 214(93\%), vomiting 196(85.2\%), nausea 183(79.6\%), abdominal distension $185(80.4 \%)$, fever $66(28.7 \%)$ and failure to pass abdominal contents, such as feces and/or flatus $138(60 \%)$ were the leading clinical symptoms among patients presenting with intestinal obstruction. (Table 3). 
Table 3

Preoperative clinical characteristics of the study participants at public hospitals of Wolayita Zone, Southern Ethiopia $(n=230)$.

\begin{tabular}{|llll|}
\hline Clinical characteristics & & Frequency & Percent \\
\hline Abdominal pain & Yes & 214 & 93.0 \\
\cline { 2 - 4 } & No & 16 & 7.0 \\
\hline Vomiting & Yes & 196 & 85.2 \\
\cline { 2 - 4 } Nausea & No & 34 & 14.8 \\
\hline \multirow{3}{*}{ Abdominal distension } & Yes & 183 & 79.6 \\
\cline { 2 - 4 } & No & 47 & 20.4 \\
\hline Fever & No & 45 & 80.4 \\
\hline Constipation & Yes & 66 & 19.6 \\
\cline { 2 - 4 } & No & 164 & 71.3 \\
\cline { 2 - 4 } & Yes & 138 & 60.0 \\
\cline { 2 - 4 } & No & 92 & 40.0 \\
\hline
\end{tabular}

Concerning the duration of illness or presentation of cases $133(57.8 \%)$ cases were presented longer than 24 hours after the onset of symptoms of intestinal obstruction. Regarding preoperative clinical diagnosis of the patients, small bowel obstruction accounts for $189(82.2 \%)$. From the total intestinal obstruction $180(78.3 \%)$ are simple obstruction the remaining are gangrenous. Regarding the causes of small bowel obstruction primary volvulus is the leading causes $60(31 \%)$. Others including adhesion, hernia and intussusception are the less common causes of SBO in the preoperative clinical diagnoses (figure 1).

\section{Intra-operative clinical characteristics}

Intussusception was the leading intraoperative clinical diagnosis of intestinal obstruction followed by simple sigmoid volvulus (SSV), gangrenous small bowel volvulus (GSBV), adhesion and band, strangulated hernia, incarcerated hernia, tumor and cancer, and gangrenous sigmoid volvulus (SBV) among others (Table 4). The commonest specific type of intraoperative procedure done after a general laparotomy, was resection and anastomosis (45.7\%) (Figure 2). 
Table 4

Intra-operative clinical diagnosis of the study participants at public hospitals of Wolayita Zone, Southern Ethiopia $(n=230)$.

\begin{tabular}{|lll|}
\hline & Frequency & Percent \\
\hline Intraoperative diagnosis & & \\
\hline Simple sigmoid volvulas & 33 & 14.3 \\
\hline Strangulated hernia & 20 & 8.7 \\
\hline Adhesion and band & 35 & 15.2 \\
\hline Intussusception & 52 & 22.6 \\
\hline Tumor and cancer & 7 & 3.0 \\
\hline Gangrenous sigmoid volvulas & 14 & 6.1 \\
\hline Simple small bowel volvulas & 23 & 10.0 \\
\hline Gangrenous small bowel obstruction & 16 & 7.0 \\
\hline Incarcerated hernia & 18 & 7.8 \\
\hline Ileosigmoid knotting & 9 & 3.9 \\
\hline Other & 3 & 1.3 \\
\hline
\end{tabular}

\section{Surgical management outcome}

The overall magnitude of favorable surgical management outcome of intestinal obstruction was found to be $177(77.0 \%)$ [ 95\% Cl, 71.4, 82.4]. (figure 3). From the total cases 18(7.8\%), 14(7.4\%), 6.1\%, and 13(5.7\%) developed facial dehiscence, anatomic leak, septic shock and pneumonia at the postoperative period respectively. The other complications are hypokalemia (3\%), organ space surgical site infection $1(0.4 \%)$, superficial incision site infection 7(3\%), and deep incision surgical site infection 10(4.3\%). Two hundred ten $(91.3 \%)$ of the cases of intestinal obstruction were improved at the discharge while $3.0 \%$ and $5.7 \%$ of cases were referred and died respectively.

\section{Factors associated with favorable surgical management outcome of intestinal obstruction}

The variables associated with favorable surgical management outcome of intestinal obstruction in the bivariate logistic regression were co-morbidity, duration of illness/presentation of cases, type of obstruction (simple or gangrenous), Diagnosis (small or large bowel obstruction) and intraoperative procedure. Out of these five variables four variables were significantly associated with favorable surgical management outcome in multivariable logistic regression analysis. These were having small bowel obstruction, having simple bowel obstruction, other procedure other than resection and anastomosis done, and early presentation of cases.

Those having small bowel obstruction were about two times more likely to have favorable surgical management outcome than those who have large bowel obstruction ( $\mathrm{AOR}=2.49)[95 \% \mathrm{Cl}, 1.91,5.12]$ and those who have 
simple bowel obstruction were about four times more likely to have favorable surgical management outcome than those who have gangrenous intestinal obstruction(AOR=4.32) $[95 \% \mathrm{Cl}, 2.00,9.3]$.

In addition, those who came earlier within 24 hours were about 4 times more likely to have favorable surgical outcome than those who came late to the hospital $(A O R=4.44)[95 \% \mathrm{Cl}, 1.99,9.92]$. Furthermore those for whom resection and anastomosis was performed were about $55 \%$ less likely to develop favorable outcome than the counterpart (AOR=0.45) $[95 \% \mathrm{Cl}, 21, .96]$ (Table 5).

Table 5

Multivariable Logistic Analysis for Factors Independently Associated with Surgical outcome of intestinal obstruction at public hospitals of Wolayita Zone, Southern Ethiopia $(n=230)$.

\begin{tabular}{|c|c|c|c|c|c|c|}
\hline \multirow[t]{2}{*}{ Variables } & \multirow[t]{2}{*}{ Category } & \multicolumn{2}{|c|}{ Surgical outcome } & \multirow{2}{*}{$\begin{array}{l}\text { COR with 95\% } \\
\mathrm{Cl}\end{array}$} & \multirow{2}{*}{$\begin{array}{l}\text { AOR with } 95 \% \\
\mathrm{Cl}\end{array}$} & \multirow{2}{*}{$\begin{array}{l}\mathrm{P} \\
\text { value }\end{array}$} \\
\hline & & $\begin{array}{l}\text { Favorable } \\
\text { OC }\end{array}$ & $\begin{array}{l}\text { Unfavorable } \\
\text { OC }\end{array}$ & & & \\
\hline \multirow[t]{2}{*}{ Diagnosis } & SBO & $151(20.1 \%)$ & $38(79.9 \%)$ & $2.71(2.51,9.49)$ & $2.49(1.91,5.12))$ & \multirow[t]{2}{*}{0.026} \\
\hline & LBO & $15(36.6 \%)$ & $26(63.4 \%)$ & 1 & 1 & \\
\hline \multirow{2}{*}{$\begin{array}{l}\text { Type of } \\
\text { obstruction }\end{array}$} & Simple & $30(15.9 \%)$ & $159(84.1 \%)$ & $6.13(3.26,14.05)$ & $4.32(2.00,9.35)$ & \multirow[t]{2}{*}{.000} \\
\hline & Gangrenous & $23(56.1 \%)$ & $18(43.9 \%)$ & 1 & 1 & \\
\hline \multirow[t]{2}{*}{$\begin{array}{l}\text { Intraoperative } \\
\text { procedure }\end{array}$} & $\begin{array}{l}\text { Resection } \\
\text { and } \\
\text { anastomosis } \\
\text { (yes) }\end{array}$ & $72(75.8 \%)$ & $55(25.2 \%)$ & $0.29(.15, .57)$ & $0.45(.21, .96)$ & \multirow[t]{2}{*}{.041} \\
\hline & $\begin{array}{l}\text { Resection } \\
\text { and } \\
\text { anastomosis } \\
\text { (no) }\end{array}$ & $90(87.3 \%)$ & $13(22.7 \%)$ & 1 & 1 & \\
\hline \multirow[t]{2}{*}{$\begin{array}{l}\text { Duration of } \\
\text { illness }\end{array}$} & $\begin{array}{l}\text { Less or } \\
\text { equal to } 24 \\
\text { hours }\end{array}$ & 79(86.8\%) & $12(12.3 \% \%)$ & $4.98(2.35,10.3)$ & $4.44(1.99,9.92)$ & \multirow[t]{2}{*}{.000} \\
\hline & $\begin{array}{l}\text { Greater than } \\
24 \text { hours }\end{array}$ & $98(70.5 \%)$ & $41(29.5 \%)$ & 1 & 1 & \\
\hline
\end{tabular}

\section{Discussion}

According to this study, moderate number of intestinal obstruction cases had favorable surgical management outcome from the total. The overall magnitude of favorable surgical management outcome of intestinal obstruction was $77.0 \%$ [ $95 \% \mathrm{Cl}, 71.4,82.4]$. This finding in line with the finding of the study conducted in Harar (78.7\%, Adama $(75.4 \%)$ and India $(74.11 \%)(11,17,20)$. This finding was higher compared with the studies conducted in eastern Ethiopia in Gelemso $(67.2 \%)$, and Nigeria $(33.5 \%)(24,26)$. However, it was lower than the 
study conducted in Kenya (86.4\%)(27). The possible explanation might be due to variation in the distribution of the clinical and socio-demographic characteristics including place of residence of the study participants, the overall infrastructures of the study area and the hospital internal setups itself, the knowledge and skill of the health professionals regarding the diagnosis and management of intestinal obstruction.

This study revealed that having small bowel obstruction was one of the factors affecting surgical management outcome of intestinal obstruction. Those having small bowel obstruction were more likely to have favorable surgical management outcome than those who have large bowel obstruction. This could be due to the fact that the fast-healing nature because of high blood supply in small bowel as well as there is high bacterial load in large intestine. This finding was supported the study conducted in Harar (6).

In addition, those having simple bowel obstruction were more likely to have favorable surgical management outcome than those who have gangrenous bowel obstruction. This could be it is obvious that the intestine is intact in simple bowel obstruction but in gangrenous obstruction there is resection part which could increase poor outcome. As well as in gangrenous obstruction the load of bacteria is high which could increase the probability of septic infection. This finding consistent with the study conducted in Harar (6).

Furthermore, for those intraoperative procedures other than resection and anastomosis were performed were more likely to have favorable outcome than the counterpart. The possible explanation for this could be when resection and anastomosis is performed it makes wound on the bowel which can increases the chance of complications like paralytic ileus, anastomotic leak and early post operation adhesion. This finding in line with the study conducted Adama (17).

Patients who came to the hospital within 24 hours were more likely to develop favorable outcomes than patients who came after 24 hours. This was consistent with studies conducted in Gondar and Adama $(17,19)$. This might be due to those who came early to the hospital have low chance of developing complication like sepsis, peritonitis, and the chance of developing gangrenous intestinal obstruction among those patients is also low. In addition, early and on time intervention for the patients increases the chance of favorability or early presentation in the case of intestinal obstruction decreases disastrous outcomes, notably a high rate of complications, long hospital stays, and high mortality.

\section{Limitation of the study}

Since the study was cross sectional study it is difficult to predict cause and effect relationship.

\section{Conclusion}

According to this study the overall magnitude of favorable surgical management outcome of $\mathrm{IO}$ in this study was moderate as compared to other study finding. Having small bowel obstruction, having simple bowel obstruction, other procedure other than resection and anastomosis, and early presentation of cases were identified as factors which were significantly associated with favorable surgical management outcome of intestinal obstruction positively. Physicians should diagnose intestinal obstruction early and appropriate interventions should be taken on time before the complication happened. On time consultation and decision at the hospital setting is also recommended. The health department should increase public awareness on intestinal obstruction through health 
education and they should also increase referral linkage at lower-level heath institution for early referral. Starting from the health center the patient referral system should not be bad because it can increase the chance of complications.

\section{Abbreviations}

AOR: Adjusted Odds Ratio, Cl: Confidence Interval, NGO: Non-Governmental Organization, OPD: Out Patient Department, OR: Odds Ratio, SBO: Small Bowel Obstruction, SPSS: Statically Package for Social Science, SSI:

Surgical Site Infection

\section{Declarations}

\section{Ethics approval and consent to participate}

Permission for data access was obtained from Wolayita Sodo University, College of Health and Medical Sciences Institutional Health Research Ethics Review Committee (IHRERC). After clear discussion about the actual study or explaining of purpose of the study, the confidentiality issues, informed consent was obtained from the study participants. Identification of study participants by name was avoided to assure the confidentiality of the information obtained. Data collectors assured that the data was handled confidentially. All methods were performed in accordance with the relevant guidelines and regulations

\section{Consent for publication}

Not applicable for this study.

\section{Availability of data and material}

The data for this study available in the correspondence author upon reasonable request.

\section{Competing interests}

The authors declare that they have no competing interests.

\section{Funding}

No-funding for this study

\section{Authors' contribution}

Proposal preparation, acquisition of data, analysis, and interpretation of data was done by M.B, B.L, ,T.B ,Y.H and S.H instruct the study design data cleaning and analysis. YH drafted the manuscript and all authors have a 
substantial contribution in revising and finalizing the manuscript. All authors read and approved the final manuscript.

\section{Acknowledgment}

First, we would like to extend our gratitude for Wolayita Sodo University, for technical support to conduct this research. Secondly, we would like to extend our appreciation to my advisor Dr Bereket Lorihiso. We also acknowledge data collectors, supervisors and participants for their respective contribution.

\section{References}

1. Julie Wilkinson, Bsn R. Bowel Obstruction Surgery: Everything You Need To Know [Internet]. 2021. P. 1-2. Available From: Rgery-For-A-Bowel-Obstruction-796815

2. Zbar Ri, Crede Wb Mc Et. A. The Postoperative Incidence Of Small Bowel Obstruction Following Standard, Open Appendectomy And Cholecystectomy: A Six-Year Retrospective Cohort Study At Yale-New Haven Hospital. Eur Mc [Internet]. 1993;57(3):123-7. Available From: Https://Europepmc.Org/Article/Med/8477590

3. Zbar Ri. Elischolar - A Digital Platform For Scholarly Publishing At Yale The Postoperative Incidence Of Small Bowel Obstruction Following Various Abdominal Procedures: A Six Year Retrospective Cohort Study At Yale-New Haven Hospital. 1992;

4. Hayes Ma. Principles Of Surgery. Vol. 115, Archives Of Surgery. 1980.

5. J.Zinner M. Maingots Abdominal Operational Operations. 2019. 1156-1170 P.

6. Derseh T. Management Outcome And Associated Factors Among Intestinal Obstruction Patients Treated Surgically, Eastern Ethiopia. :1-18.

7. Li X, Zhang J, Li B, Yi D, Zhang C, Sun N, Et Al. Diagnosis, Treatment And Prognosis Of Small Bowel Volvulus In Adults : A Monocentric Summary Of A Rare Small Intestinal Obstruction. 2017;1-8.

8. Quill Ds, Devlin Hb, Plant Ja, Denham Kr, Mcnay Ra, Morris D. Surgical Operation Rates: A Twelve Year Experience In Stockton On Tees. Ann R Coll Surg Engl. 1983;65(4):248-53.

9. Wossen Mt. Pattern Of Emergency Surgical Operations Performed For Non-Traumatic Acute Abdomen At Ayder Referral Hospital, Mekelle University, Tigrai, Ethiopia By The Year 2000-2003 Ec. 2019;9(5).

10. Tekalign Admasu G, Tilahun Beyene H, Shemsu Nuriye H. Management Outcome And Associated Factors Of Surgically Treated Non Traumatic Acute Abdomen At Attat Hospital, Gurage Zone, Ethiopia. Int J Surg Res Pract. 2019;6(2).

11. Atalay M, Gebremickael A, Demissie S, Derso Y. Magnitude, Pattern And Management Outcome Of Intestinal Obstruction Among Non - Traumatic Acute Abdomen Surgical Admissions In Arba Minch General Hospital ,. Bmc Surg. 2021;1-8.

12. Malik Am, Shah M, Pathan R, Sufi K. Pattern Of Acute Intestinal Obstruction: Is There A Change In The Underlying Etiology ? 2010;16(4):272-4.

13. Tsegaye S, Osman M, Bekele A, Tsegaye S, Hospital L. East And Central African Journal Of Surgery Volume 12 Number 1 - April 2007. 2007;12(1):53-7.

14. Gupta H, Anand S. A Study Of Forty Eight Patients With llecoceacal Mass Presenting As Intestinal Obstruction Requires Surgical Intervention And Their Outcome. 2020;7(8):2563-7. 
15. G. Ntakiyiruta1 Bm. The Pattern Of Intestinal Obstruction At Kibogola Hospital, A Rural Hospital In Rwanda. East Cent African J Surg. 2009;14(2):103-8.

16. Yohannes M, Fanta M, Molla T. Proportion Of Intestinal Obstruction And Associated Factors Among Patients With Non Traumatic Acute Abdomen Admitted To Surgical Ward In Debre Birhan Referral Hospital, North East Ethiopia. Am J Biomed Klife Sci. 2017;5(3):54-62.

17. Soressa U, Mamo A, Hiko D, Fentahun N. Prevalence, Causes And Management Outcome Of Intestinal Obstruction In Adama Hospital, Ethiopia. Bmc Surg [Internet]. 2016;1-8. Available From: Http://Dx.Doi.Org/10.1186/S12893-016-0150-5

18. Deolekar Sr, Mahapatra B, Subudhi S, Singhal P. A Study Of Surgical Management And Its Outcome In Adult Patients With Intestinal Obstruction. 2019;6(12):4370-7.

19. Mariam Tg, Abate At, Getnet Ma. Surgical Management Outcome Of Intestinal Obstruction And Its Associated Factors At University Of Gondar Comprehensive Specialized Hospital, Northwest Ethiopia, 2018. 2019;2019.

20. Ayenew Z, Gizaw At, Workneh D, Fentahun N. Outcome Of Non-Traumatic Surgical Acute Abdomen In Nekemte Referral Surgery: Current Research Outcome Of Non-Traumatic Surgical Acute Abdomen In Nekemte Referral Hospital Southwest Ethiopia : A Retrospective Cross-Sectional Study. 2017;(December 2016):8-13.

21. Tiwari Sj, Mulmule R, Bijwe Vn. A Clinical Study Of Acute Intestinal Obstruction In Adults-Based On Etiology, Severity Indicators And Surgical Outcome Original Research Article A Clinical Study Of Acute Intestinal Obstruction In Adults-Based On Etiology, Severity Indicators And Surgical Outcome. 2020;(February).

22. Awedew Af, Amsalu Bt, Belay Wb, Awedew Af, Amsalu Bt, Belay Wb, Et Al. Magnitude And Management Outcome Predictors Of Intestinal Obstruction. 2021;59(2):111-6.

23. Derseh T, Dingeta T, Yusouf M, Minuye B. Clinical Outcome And Predictors Of Intestinal Obstruction Surgery In Ethiopia: A Cross-Sectional Study. 2020;2020.

24. Bankole Ao, Osinowo Ao, Adesanya Aa. Predictive Factors Of Management Outcome In Adult Patients With Mechanical Intestinal Obstruction. Niger Postgrad Med J. 2018;

25. Soressa U. Prevalence, Causes And Management Outcome Of Intestinal Obstruction In Adama Hospital, Ethiopia. Bmc Surg. 2016;(August).

26. Abebe H. Management Outcome, Common Causes And Associated Factors Of Intestinal Obstruction In Gelemso General Hospital, Oromiya Regional State, West Harerge Zone,Ethiopia Msc. 2018;

27. (U.O.N.) Dognmbc. Adhesive Post Operative Small Bowel Obstruction In Adult Patients As Seen At The Kenyatta National Hospital.

\section{Figures}




\section{Causes of Intestinal obstruction}

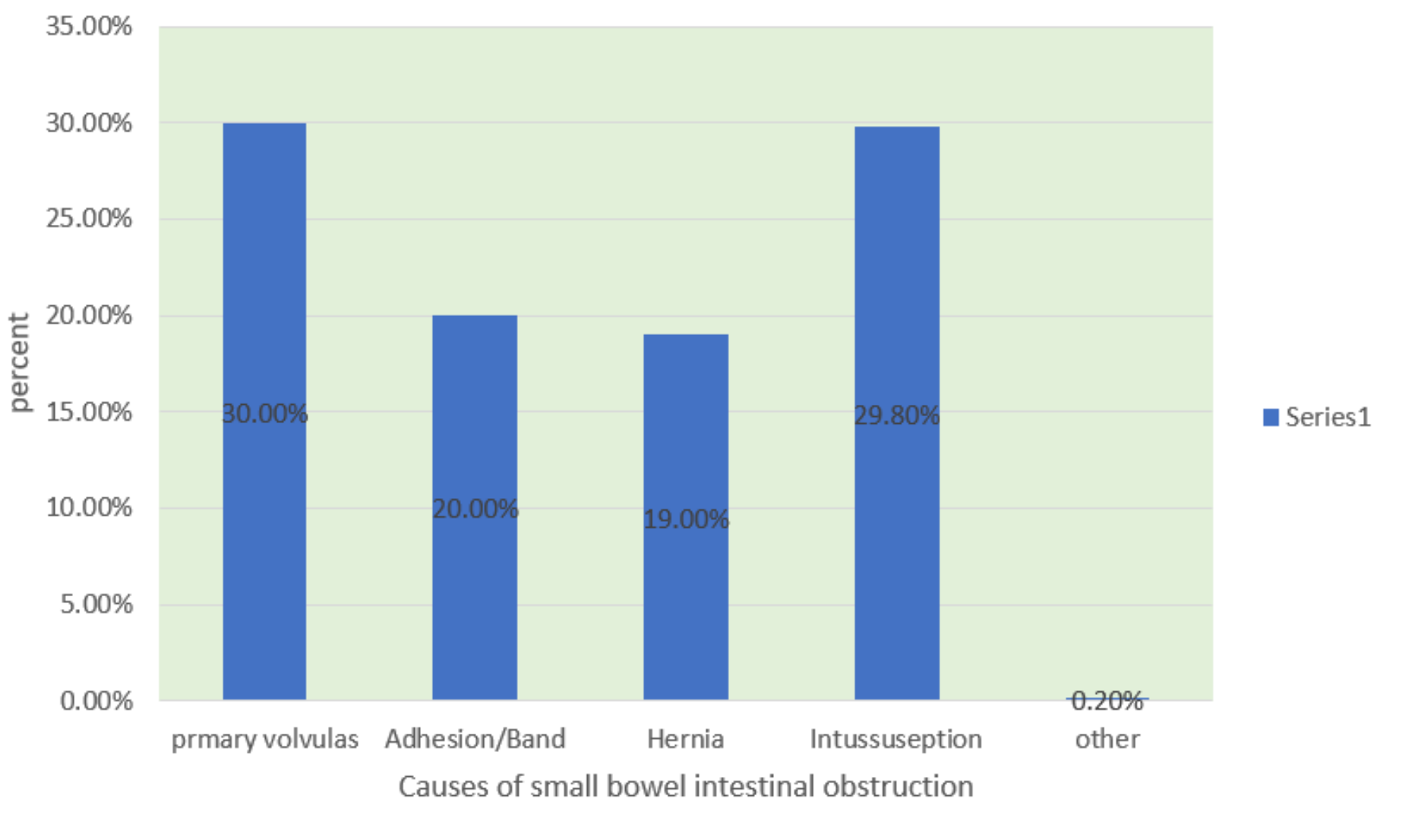

\section{Figure 1}

Causes of small bowel obstruction in the preoperative diagnosis of the study participants at public hospitals of Wolayita Zone, Southern Ethiopia $(n=230)$. 


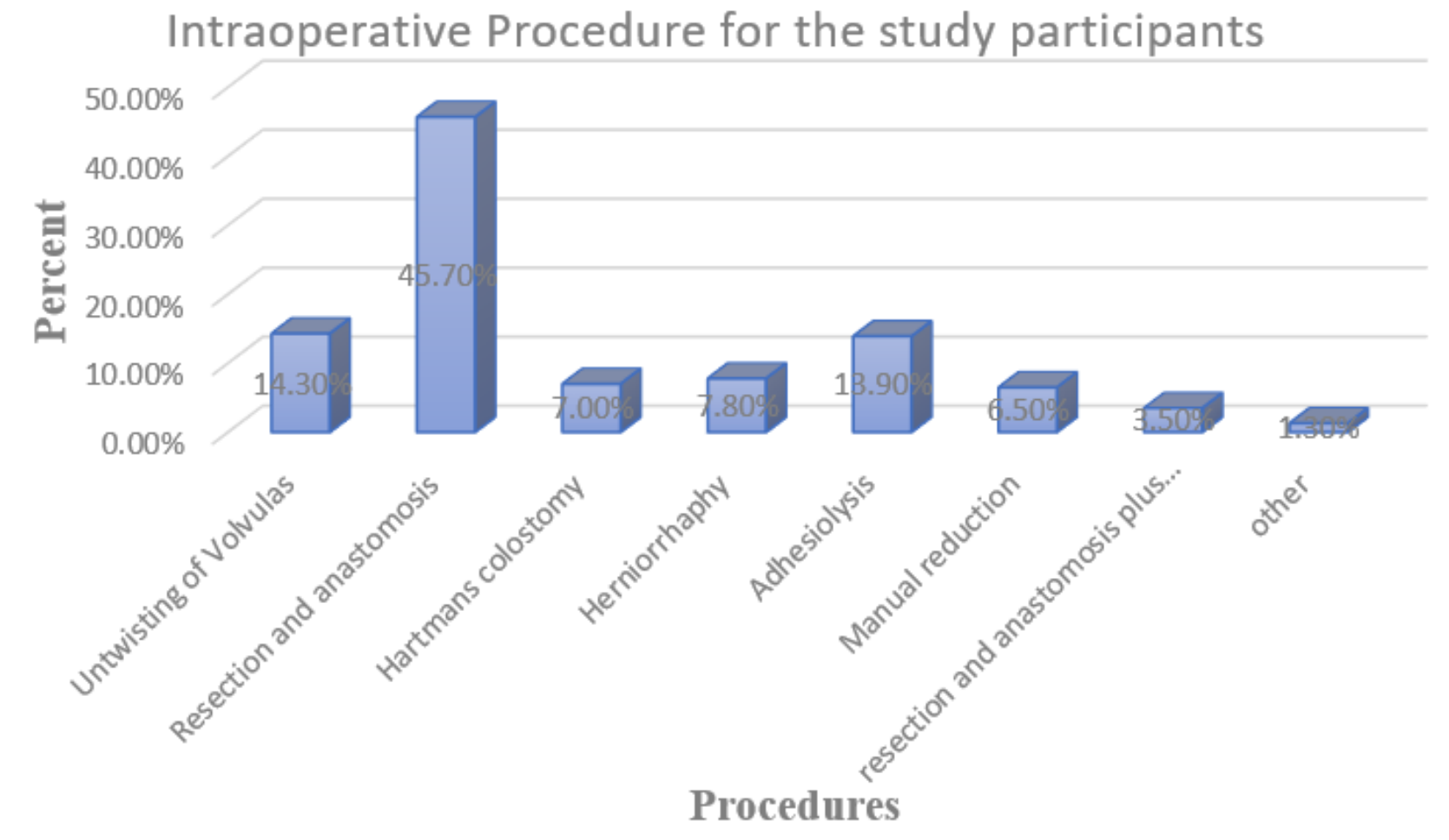

Figure 2

Intra-operative clinical procedures of the study participants in wolayita sodo referral hospital, SNNPR Ethiopia.

\section{Surgical Management Outcome}

Figure 3

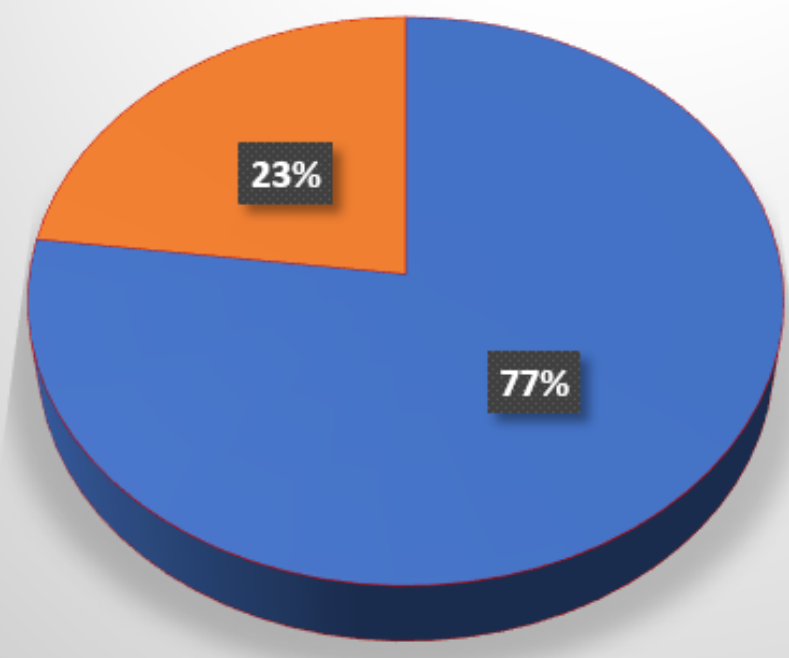

$\square$ Favorable Outcome 口Unfavorable Outcome 
Surgical Management Outcome of the study participants at public hospitals of Wolayita Zone, Southern Ethiopia $(n=230)$. 